\title{
Educação e desenvolvimento na llha do Príncipe: A cooperativa de valorização de resíduos e o seu potencial educativo
}

\author{
Olga Santos', Sofia Bergano², Mário Oliveira ${ }^{3}$ \\ ${ }^{1}$ CI\&DEI/CICS.NOVA - iACT, ESECS, Politécnico de Leiria, Portugal | \\ olga.santos@ipleiria.pt | https://orcid.org/0000-0001-9119-9278 \\ ${ }^{2}$ Centro de Investigação em Educação de Adultos e Intervenção Comunitária (CEAD), \\ Escola Superior de Educação, Instituto Politécnico de Bragança, Portugal | sbergano@ipb.pt \\ | https://orcid.org/0000-0002-9523-8884 \\ ${ }^{3} \mathrm{CI} \&$ DEI, ESECS, Politécnico de Leiria, Portugal | mario.oliveira@ipleiria.pt | \\ https://orcid.org/0000-0002-5923-3381
}

\begin{abstract}
Resumo: A Cooperativa de Valorização de Resíduos, em Porto Real - llha do Príncipe, desenvolve a sua atividade através da reciclagem de vidro, que transforma em joias artesanais, sendo este trabalho desenvolvido pelas mulheres que constituem a cooperativa. A intenção deste artigo é dar a conhecer o potencial educativo da cooperativa através do envolvimento das escolas, contribuindo para o desenvolvimento da llha, acentuando o seu papel enquanto Reserva Mundial da Biosfera. Para o efeito, foi realizado um estudo de caso de cariz qualitativo, com vista a analisar as perceções de diferentes atores sociais envolvidos. Os dados foram recolhidos através de entrevistas semiestruturadas e tratados com recurso à análise de conteúdo. Os resultados obtidos apontam para a necessidade de aproximação da cooperativa às escolas com o objetivo de sensibilizar as crianças e jovens para a necessidade de separação e reciclagem dos materiais dispersos pela llha, numa perspetiva de todos contribuírem para o seu desenvolvimento e para a minimização dos impactes ambientais existentes na mesma.
\end{abstract}

Palavras-chave: Educação; Cooperativa de Resíduos; Desenvolvimento Sustentável; Educação Ambiental.

\section{Education and Development on the Island of Príncipe: The Waste Recovery Cooperative and its Educational Potential}

\begin{abstract}
The Waste Valorisation Cooperative, in Porto Real - Príncipe Island, develops its activity through the recycling of glass, which is transformed into handmade jewellery, this work is developed by the women who make up the cooperative. The intention of this article is to show the educational potential of the cooperative through the involvement of schools, contributing to the development of the Island, emphasizing its role as a World Biosphere Reserve. For this purpose, a qualitative case study was carried out, with a view to analyse the perceptions of different social actors involved. Data was collected through semi-structured interviews and treated using content analysis. The results obtained point to the need for the cooperative to approach schools in order to sensitize children and young people to the need for separation and recycling of materials dispersed throughout the island, in a perspective of all contributing to their development and minimizing environmental impacts in the island.
\end{abstract}

Keywords: Education; Waste Cooperative; Sustainable Development; Environmenta Education.

\section{Introdução}

O estudo que agora se divulga decorreu na Reserva da Biosfera da llha do Príncipe, em São Tomé e Príncipe, mais especificamente na comunidade de Porto Real, onde se realizou uma investigação mais ampla que visava caracterizar a Cooperativa de Resíduos da llha do Príncipe. Nesta cooperativa, através da recolha e reciclagem de garrafas de vidro são produzidas joias artesanais, recorrendo ao trabalho de 11. Neste contexto, o projeto, que se considera inovador, procura dar resposta à questão da gestão de resíduos sólidos e, concomitantemente, promover o desenvolvimento local da comunidade em que se insere. 
A investigação, de cariz qualitativo, que se descreve neste artigo, tem como um dos objetivos analisar o potencial educativo desta cooperativa, numa filosofia assente na aprendizagem fora de portas em contextos não formais, junto de crianças e jovens em idade escolar, percecionado pelos atores sociais envolvidos, ao mesmo tempo que servirá para reforçar e acentuar as responsabilidades da llha enquanto reserva Mundial da Biosfera.

O projeto que enforma a cooperativa de valorização de resíduos da llha do Príncipe poderá ser um caminho para transformar a escola, constituindo-se como um espaço aberto à construção de aprendizagens significativas para todos que dele participam, promovendo ambientes de aprendizagem colaborativos, auxiliará bastante na construção de conhecimentos, habilidades e valores necessários a comunidades mais justas e sustentáveis.

Um projeto desta natureza deve reger-se por uma prática colaborativo, requerer um trabalho coletivo, onde todos os profissionais deverão estar abertos à partilha e à mudança envolvendo a comunidade local e educativa, sentindo-se comprometidos com as aprendizagens dos alunos, numa lógica de os envolver nas questões e problemas locais, sensibilizando-os para a necessidade de participação. Qualquer projeto que envolva as comunidades locais e educativas terá uma possibilidade maior de sucesso. As representações partilhadas do que os atores querem fazer juntos, serão uma mais-valia para o envolvimento de todos, sendo que este projeto em particular, carece da participação de todos os principenses para que os impactes ambientais, causados pelo vidro espalhado pela ilha, sejam minimizados, numa perspetiva de sustentabilidade deste canto do mundo, com uma beleza ímpar.

A relação humanidade-sociedade-natureza tem-se tornado incomportável do ponto de vista da gestão dos recursos, levando a uma degradação ambiental sucessiva, a uma degradação dos ecossistemas e a uma mercantilização da natureza. Como forma de mitigação dos problemas ambientais, independentemente do caráter, que poderá abarcar do social ao político, surge o termo desenvolvimento sustentável, que tem como matriz fundamental a articulação entre a prudente gestão dos recursos naturais e o direito que as populações têm à melhoria das suas condições de vida, devendo englobar a igualdade de acesso à saúde, à educação e ao emprego. Conscientes da complexidade que envolve a utilização do termo Desenvolvimento Sustentável (Silva 2008, Chetouani, 2016) tomaremos como referência a premissa de que o conceito de sustentabilidade tem que espelhar inequivocamente o equilíbrio entre o economicamente viável, o socialmente justo e o ecologicamente correto (Lamim-Guedes 2012) uma vez que esta conceção encontra-se alinhada com alguns dos textos considerados fundamentais neste domínio como o documento Década da Educação das Nações Unidas para um Desenvolvimento Sustentável (UNESCO, 2005) e o documento Nosso Futuro Comum, também conhecido como Relatório Brundtland (CMMAD, 1988). Acreditamos que é neste contexto que a Cooperativa de Valorização de Resíduos situada na comunidade de Porto Real, na llha do Príncipe, desenvolve a sua atividade através da articulação da dimensão ambiental com a dimensão social. Atendendo a que a llha do Príncipe foi declarada, pela UNESCO Reserva da Biosfera, em 2012, mais imperioso se tornou equacionar o seu presente, e futuro, numa perspetiva de sustentabilidade que se fundamenta numa lógica de intervenção a partir da comunidade.

A consideração de um paradigma de desenvolvimento comprometido ambiental e socialmente é particularmente relevante numa comunidade em que se verificam carências económicas consideráveis e em que a valorização do território e a conservação da natureza são ainda vistas como periféricas em relação a outras necessidades sentidas como mais imediatas que se prendem com a subsistência e a legítima expetativa de uma melhoria das condições de vida por parte da população. Neste sentido, as respostas comunitárias que, como é o caso da Cooperativa de Valorização de Resíduos, contribuem para a resolução de problemas ambientais e simultaneamente para melhorar as condições de vida da população, devem assumem-se como exemplos de boas práticas e como agentes ativos de promoção de educação ambiental, na comunidade em geral e, mais especificamente, junto da população em idade escolar. 


\section{Enquadramento Teórico}

\subsection{A Dinâmica Social e o Potencial Educativo Resultante dos Processos de Desenvolvimento Comunitário}

É indiscutível que o desenvolvimento da sociedade depende do desenvolvimento de cada comunidade, do seu papel, das suas escolhas e do seu dinamismo, assumidos para alcançar os objetivos e os caminhos que se propõem trilhar. Este envolvimento das pessoas está associado a dinâmicas sociais que podem convergir em capital social, definido como sendo "o poder das pessoas para fazer, coletivamente, alguma coisa" (Franco, 2004, citado por Kronemberger, 2011, p. 45). Este capital social está associado ao desenvolvimento comunitário através dos projetos que vão sendo criados e desenvolvidos (Kronemberger, 2011), devendo haver uma articulação estreita entre a implementação e desenvolvimento de todos os projetos a nível de comunidade, e o potencial educativo que lhe está associado.

As iniciativas locais criam sinergias positivas, materializadas na forma de cooperação entre pessoas, entre comunidades e entre a sociedade, governos e empresas, podendo contribuir para viabilizar o desenvolvimento comunitário (Kronemberger, 2011), envolvendo toda a comunidade, inclusivamente a educativa.

Ao conceito de desenvolvimento comunitário está subjacente um processo que tem o intuito de melhorar as condições de vida ao nível económico, social e político de uma determinada comunidade/localidade (Gómez et al, 2007). Para tal será necessário capacitar a população para que as suas práticas permitam a sua plena integração na dinâmica e desenvolvimento das comunidades em que estão inseridas. Ander-Egg (1980) define desenvolvimento comunitário como:

"uma técnica social de promoção do homem e de mobilização de recursos humanos e institucionais, mediante a participação ativa e democrática da população, no estudo, planeamento, e execução de programas ao nível de comunidades de base, destinados a melhorar o seu nível de vida (p. 69).

O envolvimento e capacitação da população é indissociável de uma nova dinâmica social que imprime um registo de novas experiências e novos projetos, que deverão ser partilhados com as escolas inseridas nas comunidades, estendendo-se gradualmente ao maior número possível de escolas. Esta partilha deverá gerar um sentimento de pertença mútuo, com potencial educativo bidirecional.

A adoção de uma estrutura organizativa flexível e aberta a cooperar com os projetos comunitários, por parte das escolas, será a chave para o sucesso (Gómez et al, 2007). Os mesmos autores advogam que "não só são possíveis, como essenciais, os compromissos de ambas as "partes" para concretizar um projeto comum e reflectir sobre como as escolas podem ensinar e ser ensinadas" (p. 245). Este conceito reforça a promoção da necessidade da educação numa perspetiva global, da cultura e das potencialidades dos recursos comunitários; e o reconhecimento de todo o seu potencial criativo e da sua capacidade de questionar a comunidade com vista ao desenvolvimento integral do individuo e do sistema comunitário (p. 246).

A participação das escolas, segundo Olsen (1954, citado por Gómez et al, 2007) seria crucial para: i) melhorar as condições e vida do lugar e da época; ii) converter a comunidade no seu laboratório de estudo; iii) prever a participação de outros agentes nos processos educativos; iv) estimular a coordenação da comunidade e v) aplicar e fomentar o espírito democrático nas relações humanas. As premissas atrás enumeradas deverão ter o envolvimento das escolas e da comunidade tendo como finalidade a melhoria coletiva (Ander-Egg, 1980). Esta ligação entre escola e comunidade constitui-se como uma necessidade para que seja possível o desenvolvimento de experiências de serviço comunitário a partir da escola, e de serviço educativo a partir da comunidade (Gómez et al, 2007). 
A necessidade de um esforço comum permitirá a criação de condições de cidadania e de bem-estar social proporcionando o desenvolvimento pleno e integral do ser humano (Caride, 2001), permitindo uma individualização do ensino, o respeito pela diversidade e a dinamização das relações da escola com o meio. A simbiose entre os serviços educativos e comunitários poderá proporcionar propostas de caráter pedagógico, social e político referindo-se às necessidades urgentes de procurar que a educação esteja mais em consonância com a vida da comunidade, alargando os seus processos educativos ao meio social e contribuir para que a escola seja parte integrante da estrutura de serviços sociais e culturais (Fessas-Emmanouil, 1978). Isto quer dizer que o conceito central do ato educativo deixa de ser a transmissão de conhecimentos, centrando-se no favorecimento da reflexão contínua das condições de vida, na prática concreta, como parte inerente do processo social e como elemento necessário para a promoção de novas atitudes e relações que estruturam a sociedade (Loureiro, 2012).

Cabe aos agentes educativos e comunitários estreitar o relacionamento entre as duas realidades, perspetivando e edificando caminhos convergentes que levem ao desenvolvimento das populações, criando sociedades de transição que poderão vir a dar um enorme contributo para a melhoria da qualidade de vida no planeta e travar a sua degradação total. Para tal é necessário adotar comportamentos de forma a que as comunidades se tornem mais resilientes perante os desafios colocados, não descurando o seu desenvolvimento, mas de forma sustentável.

\subsection{Educação e Desenvolvimento Local Sustentável}

O conceito de desenvolvimento é utilizado em diversos contextos, passando por várias transformações ao longo do tempo, entre elas a associação a vários adjetivos tais como: social, humano, sustentável, local, entre outros. O desenvolvimento local tem-se mostrado uma tendência mundial e é tema de discussão em diversos países (Kronemberger, 2011), para se tentar contrariar a indesejável degradação local.

Como foi dito anteriormente, o tema da sustentabilidade vai além da gestão dos recursos naturais. Inclui questões referentes ao sofrimento das populações decorrentes de motivos socioambientais, devido a questões financeiras, raciais, étnicas e de género e prevê uma preocupação com os direitos das gerações futuras. Neste enquadramento, o papel da mulher é considerado por alguns autores (Rabhi, 2005, citado por Castanet, Diemer \& Teulade, 2016) como relevante uma vez que representa um olhar crítico diante das origens sociais dos problemas ambientais que afetam, de forma não homogénea, os diferentes grupos e comunidades humanas (Lamim-Guedes, 2012), como é exemplo a comunidade de Porto Real, onde a cooperativa está sedeada. As questões de identidade e género, em algumas sociedades, como é o caso da maioria dos países africanos, estabelecem papéis vincadamente diferenciados para o homem e para a mulher, processo segregativo e estigmatizado, levando a maioria das mulheres a acreditar que não tem importância no processo de desenvolvimento do seu grupo comunitário, ainda que nestes contextos a organização familiar e os papéis que estão associados à vida em família, possam não ser comparáveis com os modelos tradicionais das sociedades ocidentais, como teremos oportunidade de aprofundar no enquadramento teórico.

A Educação Ambiental constitui outro eixo que consideramos fundamental nos processos que associam o desenvolvimento de uma comunidade, das pessoas que dela fazem parte e da consideração das questões ambientais, oferecendo a possibilidade de diálogo entre atores sociais e políticos, já que deve ser vista como um instrumento fundamental para ajudar na alteração de valores, mentalidade e atitudes de modo a permitir uma consciencialização profunda e duradoura, na sociedade, sobre os problemas associados com as questões ambientais (Morgado \& Leão, 2000). 
O Tratado de Educação Ambiental para Sociedades Sustentáveis e Responsabilidade Global, foca a inter-relação entre Educação Ambiental e sociedades sustentáveis, colocando a tónica na importância da Educação Ambiental ter a possibilidade de estimular a criação de sociedades socialmente justas e ecologicamente equilibradas, que conservem entre si a relação de interdependência e diversidade o que convoca a ideia de ecocidadania, ou seja, "uma cidadania consciente dos estreitos laços que existem entre sociedade e natureza, uma cidadania crítica, competente, criativa e empenhada capaz e desejosa de participar nos debates públicos, na procura de soluções e na inovação ecossocial" (Sauvé, 2016, 144). Contudo, este registo requer responsabilidade individual e coletiva ao nível local, nacional e planetário (Fórum Internacional das ONGS, 1992). Importa referir que os problemas ambientais não são democráticos (Lamim-Guedes, 2010), uma vez que se constata a existência de situações de Injustiça ambiental, que se entende como um mecanismo pelo qual as sociedades em situação de desigualdade do ponto de vista económico e social, colocam o foco dos danos ambientais referentes ao desenvolvimento, nas populações de mais baixo rendimento, grupos étnicos discriminados, populações marginalizadas e vulneráveis, assim como as mulheres (Acselrad Mello \& Bezerra 2009). As 11 mulheres que formaram a Cooperativa de Valorização de Resíduos da llha do Príncipe, espelham a importância do papel que a Educação Ambiental e a sustentabilidade podem ter, na minimização dos efeitos negativos associadas às questões de género, que por sua vez se refletem na melhoria da qualidade de vida das 11 famílias que lhes estão associadas, ao acesso à saúde, à educação dos seus filhos e à (trans)formação gradual dos hábitos da comunidade de Porto Real.

A criação de alternativas e soluções perante novos desafios reside na capacidade de se encontrarem formas eficazes de se evitar o "efeito bola de neve" de degradação local e, dessa forma, facilitar a implementação de projetos de intervenção local (Rigueiro, 2014) Neste movimento de transformação existem atores sociais significativos que dão sentido às práticas sociais locais, bem como, aos mecanismos de participação social.

O desenvolvimento local é, assim, um complexo processo que envolve a interação de fatores como desenvolvimento humano, criação de fonte de rendimento ou preservação ambiental, necessitando de um grande envolvimento das populações no que concerne à capacitação, para que possam dar o seu contributo em termos de inovação quando a atividade envolve a produção, contribuindo para uma profunda mudança pessoal e social. Desse modo, o "desenvolvimento é o movimento sinergético que consegue estabelecer uma estabilidade dinâmica em um sistema complexo, no caso, uma coletividade humana. Crescimento é movimento. Mas movimento não pode ser reduzido a crescimento" (Franco, 2005, p.6).

Para promover o desenvolvimento local sustentável numa comunidade, é imprescindível que ocorra a mobilização do grupo que nela atua, envolvendo os fatores que podem contribuir para a sua evolução, em termos económicos, políticos e sociais. Quando as iniciativas necessárias ao desenvolvimento se aproximam mais do cidadão, começam a estar criadas as condições para que este possa participar e adquirir um poder decisivo com base no conhecimento da sua realidade, havendo maior facilidade para se identificarem os problemas (Kronemberger, 2011). Jara (1998) defende que o desenvolvimento local não reflete apenas os aspetos económicos e produtivos, mas depende essencialmente da estrutura de valores que definem a cultura organizacional, da informação e do empoderamento, enquanto desenvolvimento endógeno, ou seja, baseado no aproveitamento dos recursos, das oportunidades e das capacidades locais para, e de acordo com Kronemberger (2011), "fazer acontecer". Os projetos de empreendedorismo social e local contribuem grandemente para o desenvolvimento local sustentável, mobilizando o potencial humano das comunidades locais, o potencial económico que se esconde atrás da riqueza dos recursos naturais e da riqueza do potencial humano, com o contributo da participação social e cívica, de uma forma organizada e estruturada. 


\section{Metodologia}

A intenção subjacente a este artigo é a apresentação de uma investigação de cariz qualitativo que, através da metodologia do estudo de caso, procura clarificar os contributos desta Cooperativa para a resolução de um problema ambiental, para a promoção da literacia ambiental e sobretudo para o seu potencial educativo. A escolha da abordagem interpretativa está ligada à necessidade de dar voz aos participantes do estudo, numa perspetiva que é em si mesma metodológica e epistemológica, mas também ética.

Ludke e André (1986) referem sete características para este tipo de investigação qualitativa: (1) visa a descoberta, na medida em que podem surgir, em qualquer altura, novos elementos e aspetos importantes para a investigação, além dos pressupostos do enquadramento teórico inicial; (2) enfatiza a interpretação em contexto, pois todo o estudo desta natureza tem que ter em conta as características da escola, o meio social em que está inserida, os recursos materiais e humanos, entre outros aspetos; (3) retrata a realidade de forma completa e profunda; (4) usam uma variedade de fontes de informação; (5) permite generalizações naturalistas; (6) procura representar as diferentes perspetivas presentes numa situação social; e (7) utiliza uma linguagem e uma forma mais acessível do que outros métodos de investigação.

Neste sentido, a investigação empírica que se apresenta analisa um fenómeno contemporâneo, dentro de um contexto da vida real, ou seja, perceber em que medida os atores sociais envolvidos na criação da Cooperativa de Valorização de Resíduos compreendem as suas potencialidades, não apenas como recurso económico ou como resposta a um problema ambiental concreto, mas também como uma organização capaz de contribuir para a educação e sensibilização ambiental da comunidade escolar da llha do Príncipe.

Dada a natureza dos dados e da compreensão em profundidade e extensão que deles se requer, o estudo insere-se num paradigma qualitativo.

O paradigma qualitativo permite a valorização da essência do ser humano e do dinamismo que as interações sociais comportam. Valoriza a diferença, a particularidade, a riqueza da subjetividade humana, a multiplicidade das intenções e a interioridade do pensamento, permitindo a compreensão dos sujeitos e a riqueza da sua pluralidade e diversidade (Máximo-Esteves, 2008). Um outro aspeto que importa realçar é que a análise qualitativa "es un proceso dinâmico y creativo que se alimenta, fundamentalmente de la experiência directa de los investigadores en los escenarios estudiados" (Gómez \& Martin 2009, p. 63).

Neste sentido, a abordagem metodológica, com recurso ao estudo de caso, permite constituir a comunidade como o caso em estudo e, para o efeito, foram considerados diferentes informantes que foram convidados a participar no estudo. A sua participação decorreu do reconhecimento da importância de gerar conhecimento sistemático acerca da cooperativa e da sua relevância, presente e perspetivada no futuro, na comunidade. Assim, constituiu-se um grupo de participantes diverso que incluí pessoas que tiveram papéis distintos na organização, dinamização e apoio desta cooperativa na comunidade. No quadro 1 elencam-se os participantes e a técnica de recolha de dados utilizada, a saber: entrevistas semiestruturadas individuais e em grupo focal. 
Quadro 1. Participantes e técnicas de recolha de dados

\begin{tabular}{llll}
\hline \multicolumn{1}{c}{ Participantes } & Técnica de recolha de dados & n. & Código \\
\hline "Primeira" responsável pelo projeto & Entrevista individual & 1 & E \\
Responsável político & Entrevista individual & 1 & PC \\
Responsável pela cooperativa & Entrevista individual & 1 & B \\
Restantes trabalhadoras da cooperativa & Focus group (grupo focal) & 10 & FG1a FG10 \\
\hline
\end{tabular}

Foram considerados os participantes elencados com o intuito de: (1) representar os diversos atores sociais envolvidos; (2) explicitar os diferentes níveis de decisão, (3) perceber as dinâmicas de poder entre os atores envolvidos, (4) perceber o contributo direto de cada um dos participantes na cooperativa. A escolha deste grupo de participantes permite a identificação e triangulação de perspetivas complementares sobre o papel desempenhado por este tipo de organizações na própria comunidade e na perspetiva que cada um destes atores sociais tem sobre as necessidades e oportunidades de promover a educação ambiental através dos recursos da comunidade, envolvendo as pessoas na construção de uma cultura respeitadora do ambiente e socialmente comprometida com a educação para a transformação social.

Todos os participantes concordaram em participar na investigação depois de explicitados os seus objetivos, o âmbito em que seriam divulgados os resultados assim como a forma como são identificados (de forma a manter o anonimato possível). As entrevistas semiestruturadas foram feitas a partir de um guião construído tendo como referência os objetivos de uma investigação mais vasta sobre a cooperativa, no qual foram considerados diversos blocos de questões com diversas questões abertas inspiradas na revisão da literatura e na análise documental de diversa documentação do projeto em análise. O presente artigo foca-se no bloco de questões relativo à potencialidade da cooperativa de Valorização de Resíduos no domínio da educação ambiental e, mais especificamente, da população em idade escolar.

Os dados recolhidos através das entrevistas (individuais e em grupo focal) foram transcritos para se proceder a uma análise de conteúdo, seguiu-se um processo de categorização, que deu origem à definição de categorias e subcategorias a posteriorique materializaram a lógica de organização das respetivas unidades de registo, oriundas dos discursos dos participantes, no sentido de permitir a sua análise sistemática.

\section{Apresentação e discussão dos resultados}

Através da análise dos dados recolhidos, no que concerne ao potencial educativo da cooperativa de valorização de resíduos da llha do Príncipe, foram constituídas três categorias, a saber: i) constatação de ausência de ligação às escolas; ii) necessidade de sensibilização ambiental da comunidade; e iii) estratégias para a desenvolver;

Relativamente à primeira categoria constatou-se que até ao momento da recolha de dados, nenhuma escola tinha ainda visitado as instalações da cooperativa, não existindo qualquer envolvimento entre as duas instituições. O motivo desta ausência terá a ver com a falta de motivação e divulgação referidas pelas trabalhadoras da cooperativa e também pela falta de iniciativa tal como demonstra as transcrições que se seguem:

FG1, FG2, FG3, FG4, FG5: "Não, nunca tivemos nenhuma visita de escolas aqui" (em coro).

\section{FG3: "Não [fazem visitas]"}

A segunda categoria que emergiu dos dados (necessidade de sensibilização ambiental da comunidade) foi dividida em duas subcategorias, uma respeitante à perceção da necessidade de sensibilizar a comunidade escolar, designadamente professores e estudantes, e outra relativa à necessidade de sensibilizar a comunidade em geral. 
Relativamente às escolas, verifica.se que tanto as mulheres trabalhadoras como os outros informantes reconhecem esta necessidade, como se ilustra de seguida:

FG4: "Há coisas que o professor pode fazer sem ter que pedir autorização e não faz...eu se fosse professora fazia assim"

FG1: "Lá na escola tem contentor para crianças porem lixo, então vinha aqui ver o que acontecia às garrafas que separavam na escola..."

FG5: "Falta de interesse, falta de divulgação, professor (...) precisa de formação"

PE2: “... poucos professores têm iniciativa para envolverem os alunos nessas coisas..."

FG5: "Quando estão a falar de meio ambiente e de garrafa, podiam vir aqui para ver"

PE2: “...elas próprias também têm que ter a iniciativa para trabalharem e envolverem as escolas. Os dois estão a falhar"

PE1: "mais campanha de sensibilização... nas escolas [para ajudar a resolver os problemas ambientais da ilha].

$\mathrm{E}$, ainda que com menos expressão, a subcategoria relativa à necessidade de sensibilizar a comunidade no geral está visível no discurso que se transcreve:

PE1: "mais campanha de sensibilização [para ajudar a resolver os problemas ambientais da ilha] só o nosso trabalho não é suficiente porque nós temos pessoas que quando bebem uma bebida, preferem jogar a garrafa no chão do que no caixote"

A análise do discurso das senhoras que trabalham na cooperativa permite observar que têm noção do potencial educativo que a mesma representa para os alunos das escolas e da necessidade de reforçar as oportunidades de educação ambiental da comunidade.

Por fim, salienta-se a terceira categoria - estratégias a desenvolver - que se manifesta nas seguintes transcrições:

FG5: "...precisa de divulgar mais..."

PE2: “...se as senhoras não se apropriam do projeto e não sabem o valor que ele..."

PE2: "...e pensar numa forma de divulgar o seu trabalho..."

A apropriação e divulgação do projeto por parte das senhoras que trabalham na cooperativa, será fundamental para desempenharem o seu compromisso social com as escolas, cativando-as e envolvendo-as, vincando o seu potencial educativo em matéria de sensibilização ambiental, que deveria ser operacionalizado com as visitas dos professores e alunos às instalações, onde o vidro é transformado. As ideias que acabamos de expressar estão espelhadas nas transcrições que se seguem:

Considerando a interceção dos resultados salienta-se que a divulgação do trabalho, tal como refere PE2 é importante. Contudo, a postura das escolas também terá de ser flexível e aberta para poderem cooperar com os projetos comunitários, uma vez que o sucesso dependerá da entrega das instituições envolvidas partindo do princípio que "as escolas podem ensinar e ser ensinadas" (Gómez et al, 2007, p.245).

Sabe-se o quão profícuo é para os alunos a aprendizagem fora de portas e neste caso concreto. Referimo-nos a aprendizagens que podem ditar a qualidade de vida e de sobrevivência dos habitantes da llha. Talvez a cooperativa deva "...cativar as escolas para irem visitar, para as escolas também terem interesse..." PE2, uma vez que e como refere novamente PE2,

PE2: "elas têm uma parte social que é fornecer este conhecimento às escolas e elas ainda não chegaram a esta fase" 
PE2: "tem a ver com o que eu disse anteriormente sobre a apropriação do projeto, se as senhoras não se apropriam do projeto e não sabem o valor que ele representa, tanto em termos financeiros como ambientais e ter uma regra de trabalho, e pensar numa forma de divulgar o seu trabalho e cativar as escolas para irem visitar para as escolas também terem interesse..."

PE2: "Elas é que trabalham lá no dia-a-dia. Sabem qual é o tipo de trabalho. Têm a noção que estão a recolher resíduos e a transformar, em linguagem simples, elas conseguem transmitir esses valores [às crianças e professores]"

PE2: "[Ainda que tenham uma escolaridade baixa] conseguem, conseguem [fazer passar a mensagem]. Qualquer um percebe o que elas estão a fazer desde que se apropriem de todo esse valor que tem este projeto.

Parece-nos que a apropriação do projeto, por parte das senhoras, será a chave do sucesso para que as escolas se aproximem da cooperativa e haja uma partilha efetiva de saberes. Acreditamos também que o envolvimento de todos os professores será fundamental para que se crie uma simbiose entre as duas partes e os alunos possam, presencialmente, ver a continuidade do trabalho que iniciam nas escolas e a importância da reciclagem das garrafas de vidro, atribuindo-lhe a devida importância.

O intercâmbio de conhecimento dos diferentes intervenientes poderá proporcionar propostas de atividades de caráter pedagógico e social, procurando que a educação se envolva diretamente com a realidade da comunidade, ao mesmo tempo que a escola deverá alargar os seus processos educativos ao meio social, fazendo parte integrante da estrutura de serviços sociais e culturais (Fessas-Emmanouil, 1978). Isto implica uma mudança de paradigma, ao substituir-se o conceito central do ato educativo baseado na transmissão de conhecimentos, colocando a tónica na importância da reflexão sobre as temáticas atuais e reais de cada sociedade, na prática concreta, como parte inerente do processo social e como elemento imprescindível para alavancar novas atitudes e relações que estruturam as sociedades, tal como referem os trabalhos de (Loureiro, 2012).

\section{Considerações finais}

O presente trabalho constitui um pequeno contributo para a divulgação de um projeto que articula a tentativa de dar resposta a um problema ambiental, no caso a gestão de resíduos, e que simultaneamente poderá ser um laboratório vivo de experiências de aprendizagem, se articulado com as escolas e a comunidade educativa, melhorando o sistema educativo no que diz respeito à situação de muitos países em desenvolvimento.

Do ponto de vista da educação ambiental salientamos a relevância de divulgar projetos que se fundamentam em lógicas não tradicionais de resolução das questões dos resíduos, destacando que é possível aliar as preocupações ambientais com ganhos educativos, sociais e económicos que revertem diretamente para a população, que melhoram as suas condições de vida e que contribuem de forma significativa para a capacitação e valorização das pessoas e dos territórios.

Parece-nos que com o potencial educativo que a cooperativa possui, poderá contribuir para a formação de alunos mais solidários, democráticos e capazes de desenvolverem um espírito de interajuda. A cooperativa poderá contribuir para um papel importantes na construção de um tipo de convivência social, onde a democratização das oportunidades seja acompanhada da democratização dos resultados obtidos pelas comunidades.

A convivência, o respeito mútuo, a solidariedade, a promoção da justiça social, a igualdade, a autonomia, a cooperação e a realização de objetivos comuns, poderão ser valores que em contexto insular, num território tão pequeno como é o caso da llha do Príncipe, poderá ter resultados muito positivos numa perspetiva de cidadania e empreendedorismo, perspetivando-se a ajuda do próximo e da comunidade. 


\section{Referências}

Acselrad, H., Mello, C. C. A. \& Bezerra, G.N. (2009). O que é Justiça Ambiental? Garamond.

Ander-Egg, E. (1980). Metodologia y pratica del desarollo de la comunidade. (10ํed.). UNIEUROP

Caride, J. (2001); La educación ambiental en el desarrollo humano: horizontes para la sustentabilidad ecológica y la responsabilidad social. Centro Nacional de Educación Ambiental. Universidad de Santiago de Compostela, España

Castanet, G., Diemer, A., \& Teulade, J. (2016). A educação para o desenvolvimento sustentável, na sobriedade feliz da quinta do centro les Amanins: o grande projeto de Pierre Rabhi. In A. Diemer, e C. Marquat (Org.) Educação para o desenvolvimento sustentável: desafios e controvérsias (pp. 419-439). Edições Piaget.

Chetouani, L. (2016). Conceptualização da noção de "desenvolvimento sustentável" no contexto da EDS: uma questão de vocabulário. In A. Diemer, e C. Marquat (Org.) Educação para o desenvolvimento sustentável: desafios e controvérsias (pp. 37-61). Edições Piaget.

Comissão Mundial sobre Meio Ambiente e Desenvolvimento (CMMAD). (1988). Nosso futuro comum. Fundação Getulio Vargas.

Fessas-Emmanouil, H. D. (1978). La cuestión de la integración de los servicios educativos y comunitários. Perspetivas. Vol. VIII, n.4.

Fórum Internacional das ONGS. (1992). Tratado de educação ambiental para sociedades sustentáveis e responsabilidade global. Rio de Janeiro: Consultado em 18 novembro 2018. Disponível em http://portal.mec.gov.br/secad/arquivos/pdf/educacaoambiental/tratado.pdf

Franco, A. (2005). Pobreza e Desenvolvimento Local. Consultada em https://pt.scribd.com/document/223298477/Franco-Augusto-Pobreza-e-DesenvolvimentoLocal-pdf, dia 20 de março de 2018.

Gómez, J. A. C., Pereira de Freitas, O. M., \& Callejas, G. V. (2007). Educação e desenvolvimento comunitário local. Perspetivas pedagógicas e sociais da sustentabilidade. Profedições, Lda.

Gómez, M., \& Martín, P. (2009). Herramientas Conceptuales y Analíticas en las Metodolologías de Investigación. El Análisis Cualitativo. In S. Salazar, \& M. Gómez (Coords.). Investigación y Formación. Teoria y Práctica De La Investigación Educativa En La Formación De Educadores. Vol. I. (pp. 61-94). Universidad Salamanca. AECI.

Jara, C. J. (1998). A sustentabilidade do desenvolvimento local. Secretaria de Planejamento do Estado de Pernambuco.

Kronemberger, D. (2011). Desenvolvimento local sustentável: uma abordagem prática. Editora Senac.

Lamim-Guedes, V. (2010). A importância da justiça ambiental frente à injustiça da crise ambiental. Boletim Diário Ecodebate. Disponível em http://www.ecodebate.com.br/2010/01/27/aimportancia-da-justica-ambiental-frenteainjustica-da-crise-ambiental-artigo-de-valdir-lamimguedes/

Lamim-Guedes, V. (2012). Consciência negra, justiça ambiental e sustentabilidade. Sustentabilidade em Debate, v. 3, 223-238.

Loureiro, C. F. B. (2012). Sustentabilidade e Educação: um olhar da ecologia política. São Paulo: Cortez editora.

Ludke, M. \& André, M. E. D. A. (1986). Pesquisa em educação: abordagens qualitativas. Editora EPU.

Marques, S. J. (2012). Perspetivas antropocêntricas e ecocêntricas da estética ambiental: contributos para a sustentabilidade. Philosophica, 40, 43-56. 
Máximo-Esteves, L. (2008). Visão Panorâmica da Investigação-Acção. Porto Editora.

Morgado, F., \& Leão, R. P. F. (2000). Educação Ambiental. Para um ensino interdisciplinar e experimental da Educação Ambiental. Plátano Edições Técnicas.

Rigueiro, I. C. (2014). Desenvolvimento Local Sustentável: Uma abordagem à sustentabilidade dos Projetos de Empreendedorismo Social. Coimbra. Tese de mestrado não publicada.

Sauvé, L. (2016). Quais os fundamentos de uma educação para a cidadania? Desenvolvimento sustentável e "viver bem": propostas contrastadas. In Educação para o desenvolvimento sustentável: desafios e controvérsias, editado por Arnaud Diemer e Christel Marquat, (pp. 129-147). Edições Piaget.

Silva, M. (2008). Globalização, pobreza e género. In F. Henriques (Coord.) Género, Diversidade e Cidadania (pp. 119-129). Lisboa: Edições Colibri/CIDEHUS-UE.

Sousa, M. J., \& Baptista, C. S. (2011). Como Fazer Investigação, Dissertações, Teses e Relatórios. Pactor.

UNESCO (2005). Década da Educação das Nações Unidas para um Desenvolvimento Sustentável. 2005-2014: documento final do esquema internacional de implementação. 